\title{
El sistema de financiación local español: principios constitucionales que lo delimitan ${ }^{1}$
}

\author{
Fernández Pavés, María José *
}

\section{Resumen}

En el presente trabajo se abordan, desde una perspectiva necesariamente esquemática dadas sus características, los principales criterios que delimitan y perfilan el sistema de financiación local vigente en España, fundamentalmente a través de la referencia a los principios constitucionales que configuran el poder tributario de los entes locales en nuestro pais; para ello, partimos de la definición que da nuestra norma suprema sobre el deber general de contribuir al sostenimiento de las gastos públicos, de acuerdo a la capacidad económica de los ciudadanos, mediante un sistema tributario justo inspirado en los principios de igualdad y progresividad, aunque sin alcanzar carácter confiscatorio. Junto a lo anterior, es necesaria la referencia al principio constitucional de legalidad tributaria, de tan trascendentales consecuencias en esta materia; así como a los específicamente señalados en la norma de referencia para el ámbito estrictamente local, tales como la autonomia de gestión y la consiguiente autonomía financiara, y la suficiencia de recursos junto a la definición de un sistema mixto de financiación, que se nutrirá fundamentalmente de tributos propios, y de la participación en ingresos de otros entes, Estado y Comunidades Autónomas. De todo lo cuál resulta necesariamente el carácter derivado que tiene, en nuestro país, el poder tributario de las Corporaciones locales, al ser el que ha de respetar mas limitaciones en su ejercicio, y sobre todo, de mayor relevancia tributaria.

Palabras clave: Principios constitucionales, sistema de financiación, autonomía local.

Recibido: 01-01-26 . Aceptado: 01-04-16

Profesora Titular de Derecho Financiero y Tributario de la Universidad de Granada (España). E-mail: fpaves@ugr.es

1 Este trabajo tiene su origen en la Comunicación que presentamos al V Congreso Iberoamericano de Municipalistas: "Municipio y Globalización: riesgos y oportunidades", celebrado en Baeza (España), del 19 al 23 de septiembre de 2000, con las correcciones y adaptaciones oportunas. 


\section{The Spanish System of Local Financing: Constitutional Principles That Limit This System}

\section{Abstract}

In this paper we touch on the principal criteria that limit and give form to the Spanish system of local financing, from a necessarily schematic perspective due to its characteristics. This is done fundamentally through reference to those constitutional principles that construct tributary powers in these local entities in the country. We begin with the definition of the supreme overall norms in reference to the general duty to contribute to the maintenance of public expense according to the economic capacity of each citizen, through a just taxation system inspired by the principles of equality and progression, without a confiscation character. Together with this it is necessary to refer to the constitutional principle as to the legality of taxation which is of transcendental importance, as well as what is specifically referred to with respect to local authority, such as autonomy of action, financial autonomy, and the necessity of resources together with the definition of a fixed system of financing which is fed principally from taxation, as well as from participation in the financing of other agencies such as the national government and autonomous communities. All of this points to the need in our country for taxation authority in local corporations, respect for the limitations in its usage, and above all, more taxation relevance.

Key words: Constitutional principles, financing systems.

\section{Introducción}

El sistema de financiación local debe ser incardinado necesariamente para su estudio, en el conjunto de entes públicos territoriales que forman el Estado español en nuestro caso, para que exista un necesario equilibrio entre todos ellos, Estado propiamente dicho, Comunidades Autónomas y Corporaciones locales, a la hora de configurar y definir su respectivo sistema de obtención de ingresos para hacer frente a sus gastos públicos, en aras a dar cobertura a los servicios públicos y finalidades de interés general de su competencia en cada uno de estos casos. Esta idea resulta evidente, la financiación de cada una de esas entidades dependerá, a su vez, de la correspondiente al resto, al ser lógicamente finito el volumen de los recursos económicos a repartir entre todas ellas, y coincidir el contribuyente local con el autonómico y estatal, por ser, a su vez, el mismo sujeto.

Lo anterior no cambia, lógicamente, en esencia, por la diferente estructura territorial interna en la que se puedan organizar políticamente los diferentes Estados; puesto que la existencia de más o menos entes públicos territoriales dentro de un país, entre el propio ente central, posibles Estados Federados, entidades regionales y corporaciones locales de diversa entidad y envergadura, independientemente de la denominación especifica recibida por cada uno de ellos; sólo simplifica o, por el contrario, complica algo más esa necesaria estructuración y, por ende, el necesario equilibrio en el re- 
parto de competencias y funciones asumidas, así como en la distribución y asignación de recursos económicos ofuentes de ingresos disponibles para si financiación.

Concretamente, respecto de la situación de nuestro país, parece haber acuerdo hasta el momento sobre que las Entidades locales entre todas las posibles, tienen pendiente una verdadera reestructuración en profundidad de su sistema fiscal, una vez cerrada de momento, aunque no definitivamente, la financiación autonómica española. Dista mucho todavía este tercer nivel, de alcanzar esos números hipotéticos de reparto ideal que tanto se han manejado $y$, de manera tan recurrente se han traído a colación en numerosas ocasiones al respecto, consistentes en el $50 \%$ aproximadamente de recursos para el Estado y, el 25\% respectivamente, de medios disponibles para las Autonomias y Entes locales, que incluso ya han sido puestos en cuestión en nuestro caso, hacia la rebaja del porcentaje estatal.

Este diseño fundamental de la estructuración interna territorial de los países, en cuanto a la financiación de servicios públicos, necesidades colectivas y finalidades de interés general, debe partir necesariamente en todos los casos, de la precisa referencia a la norma suprema o cúspide de la pirámide normativa que preside el Derecho de cada Estado, en nuestro caso la Constitución española de 1978 como norma superior de nuestro ordenamiento jurídico; analizando para ello los principios, límites y criterios que deben presidir el sistema de financiación local, en este caso, que a pesar de su vinculación directa a la situación española, creemos puede ser ilustrativo en cualquier caso, como punto de referencia para el análisis detallado y estudio pormenorizado de otros ordenamientos, dadas las grandes semejanzas y proximidades existentes entre muchos de ellos, como es el caso de los correspondientes a paises tan cercanos y vinculados a nuestra trayectoria jurídica y económica, como son los hispanoamericanos, y entre ellos especiaimente Venezuela.

\section{Los principios constitucionales de Justicia Tributaria}

El art. 31-19 de la Constitución ${ }^{2}$. establece los principios de justicia tributaria, los cuales en realidad son aspectos parciales de un principio general: la justicia financiera, plasmada en ese primer párrafo respecto de los tributos $y$, en el siguiente en relación al gasto público; de ahí la interconexión entre todos ellos que imposibilita un análisis aislado de cada uno, necesitándose relacionar con los demás a la hora de su estudio particular. Esos principios no son meramente criterios directivos u orientadores del ordenamiento tributario, como económica mediante un sistema tributario justo inspirado en los principios de igualdad y progresividad que, en ningún caso, tendrá alcance confiscatorio». 
ocurriría si permaneciesen sólo como principios generales del Derecho sin normativizar; sino por el contrario, conllevan auténticas normas jurídicas aplicables y además de rango superior, al estar consagrados en la Constitución, por que vinculan tanto a los poderes públicos como a los ciudadanos, por otro lado, poseen una eficacia limitativa material para el legislador al dictar el resto de normas tributarias, puesto que deberá respetarlos al regular los tributos que integran el sistema por su rango supremo; por supuesto, deben ser respetados por los órganos de la Administración tributaria en su actuación aplicativa del ordenamiento, a la hora de velar por la aplicación y cumplimiento de los tributos, asi como por los ciudadanos o sujetos obligados a su pago al cumplir con sus deberes y obligaciones tributarios e, igualmente podrán alegarse ante los Tribunales de justicia, como máximo intérprete ante el Tribunal Constitucional, si se consideran violentados por el contenido de las normas tributarias ordinarias o incumplidos por los órganos administrativos al impulsar su aplicación.

\subsection{La generalidad en el pago de los tributos}

Este primer principio, plasmado también en el art. 3 de la Ley General Tributaria (1963) (LGT), lo identificamos en la referencia inicial del citado precepto constitucional e, implica de entrada que, todos los ciudadanos deben concurrir al levantamiento de las cargas públicas, todos están llamados al sostenimiento del gasto público y para ello deben contribuir con el pago de los tributos. En relación con el principio de igualdad, puesto que todos deben contribuir por igual $y$, con el de capacidad económica, por suponer que no todos deban pagar material y efectivamente en todos los casos ni la misma cuantía, sino aquellos que muestren su aptitud para contribuir de acuerdo a su capacidad y en relación a ella; ya que como ha dicho el Tribunal Supremo $(1986)^{3}$,las características de este principio son la abstracción y la impersonalidad.

Su esencia está en la exclusión de privilegios fiscales injustos desde el plano de la Constitución; prácticamente lo que se prohíbe es eximir a alguien del pago del tributo privilegiadamente, no la existencia de cualquier excepción al pago generalizado de los tributos por todos, sino de privilegios fiscales injustos, no legítimos. Estos se podrian llevar a cabo, bien por dejar fuera de la definición del hecho imponible del tributo, puestos fácticos que son equiparables a los contenidos en la misma sin razón objetiva fundamentada unos casos nacería el tributo y en otros no, por tanto; o bien lo más frecuente, por la vía de las exenciones subjetivas, suponen dejar de pagar el tributo para

3 "La generalidad como principio de ordenación de los tributos... No significa que cada figura impositiva haya de afectar a todos los ciudadanos. Tal generalidad, caracteristicas del concepto de Ley es compatible con la regulación de un sector o de grupos compuestos de personas en idéntica situación. Sus notas son la abstracción y la impersonalidad; su opuesto la alusión intuitu personae...". 
ciertos sujetos o grupos de ciudadanos en todo o en parte, aún habiendo realizado su hecho imponible.

Luego para saber cuándo se respeta dicho principio y cuándo no, qué excepciones no violan dicho principio de generalidad y cuáles sí, el criterio será sustancial, el fundamento juridico de dicha excepción; si se basa en otro principio de justicia tributaria como puede ser el de capacidad económica o, en algún principio o criterio constitucional en general, que consagre, garantice y proteja nuestra norma supre$\mathrm{ma}^{4}$, no irá contra la generalidad en el pago de los tributos, de lo contrario sí. $Y$ sin olvidar al respecto, que esa prohibición de privilegios fiscales injustos por injustificados, no opera solamente a nivel individual sino también debe tenerse en cuenta territorialmente, es decir, entre las distintas Comunidades Autónomas así como Corporaciones Locales que forman el pais, por los límites constitucionales fijados; aunque no lo sean los derechos históricos forales $u$ otras situaciones especificas que también garantiza la Constitución por considerarlas justificadas ${ }^{5}$.

\subsection{El principio de igualdad tributaria}

La formulación genérica del principio de igualdad tributaria podría ser que los ciudadanos son iguales a la hora de contribuir al sostenimiento de los gastos públicos, siempre que esa igualdad no sea simplemente aritmética o cuantitativa; sino que su verdadero alcance exige el tratamiento igual entre iguales tanto como el trato desigual, entre los desiguales, atendiendo precisamente a su capacidad económica 0 , lo que es lo mismo, no permite tratos diferenciados si no se basan en situaciones de desigualdad real, mientras que por el contrario, los exige si se dan verdaderas desigualdades. A nivel constitucional este principio recibe respaldo desde distintos puntos de vista: en el art. $11^{\circ}$ se recoge como uno de los valores superiores de nuestro ordenamiento jurídico; el art. 9-20 por su parte, lo proclama como una situación a alcanzar de forma real y efectiva entre los individuos y los grupos, para lo cuál los poderes públicos deben promover las condiciones necesarias; además, el art. 14 nos dice que ha de ser la regla de tratamiento que reciban los ciudadanos en las normas jurídicas $y$, el art. 31-10 finalmente, lo regula como uno de los principios de justicia tributaria.

Como señaló el Tribunal Constitucional (1987) tanto el Art. 31 de la Constitución como el Art. 14 y el art. $9-2^{\circ}$ de la

4 Como por ejemplo, los criterios rectores de la política social y económica (art. 40: pleno empleo, art. 42: retorno de los emigrantes, art. 45: protección del medio ambiente, ...); o la inmunidad fiscal de agentes diplomáticos y de organizaciones internacionales (art. 96: eficacia de los tratados intemacionales y criterio de reciprocidad); o las exenciones a la Iglesia Católica y otras Confesiones Religiosas (art 16: libertad religiosa), junto con otros muchos.

5 Al estar consagrados constitucionalmente por las Disposiciones Adicionales Primera y Tercera los derechos históricos de los territorios formales y el régimen económico y fiscal del archipiélago canario, respectivamente, y por su Disposición Transitoria Quinta para las ciudades de Ceuta y Melilla. 
misma, son reflejo de ese valor superior del ordenamiento jurídico consagrado en su Art. 1, sin embargo, no todos ellos tienen el mismo alcance ni eficacia; mientras el Art. 14 consagra la igualdad ante la ley y la interdicción de las discriminaciones por razón de nacimiento, raza, religión, sexo, opinión, o cualquier otra circunstancia personal o social, desempeñando por tanto, un papel claramente instrumental, como criterio exclusivamente formal en cuanto al reflejo de los ciudadanos en la legislación en general; el art. 31 contempla la igualdad como un criterio material de justicia tributaria en este caso, que inspira todo el sistema tributario, la obligación de contribuir al sostenimiento de los gastos públicos de forma igualitaria.

En este sentido el Tribunal ha avanzado, el derecho a la igualdad tributaria no debe ser considerado sólo como formal, "igualdad ante la ley", sino además con contenido sustantivo, "iguaidad en la aplicación de la ley". Por este último precepto, la diferencia o diversidad no significa siempre y necesariamente discriminación, io que sí sucede en el art. 14; sólo será discriminatoria la diferencia de trato que carece de fundamento juridico suficiente, es decir, constitucional. Luego el principio de igualdad como inspirador del ordenamiento tributario, aporta el mandato de la prohibición de diferencias que resulten discriminatorias por infundadas, sobre todo en atención a la capacidad económica de los sujetos; el Tribunal Constitucional (1987 y 1988), ha dicho que "la realidad social desigual legitima el trato claramente discriminatorio (sic) arbitrado por la ley", que "puede exigir un mínimo de desigualdad formal para progresar hacia la igualdad sustancialm.

\subsection{Las exigencias de la capacidad económica}

Se suele afirmar tradicionalmente que este principio es el más trascendental de los principios de justicia tributaria consagrados en el art. $31-1^{\circ}$ de la Constitución y, también reflejado en el art. 3 LGT, es el principio por antonomasia; también se habla de la capacidad contributiva, idea utilizada en muchas ocasiones como equivalente y que sin embargo implica una idea algo diferente. La capacidad económica supone ante todo la manera de concretar y formular la idea de justicia tributaria, siendo el criterio que preside como vimos el reparto justo de la carga tributaria; como ha dicho el Tribunal Constitucional (1981, Sentencia no 27 de 20 de julio) * $/ a$ capacidad económica, a efectos de contribuir a los gastos públicos, significa tanto como la incorporación de una exigencia lógica que obliga a buscar la riqueza alli donde ésta se encuentre".

Distinto será la capacidad contributiva o aptitud general y previa para contribuir de forma abstracta al sostenimiento del gasto público y por tanto al mantenimiento del propio sistema, que no sólo ni necesariamente se traducirá en una obligación de pago, en una prestación pública patrimonial; sino que implica una contribución global con todas las prestaciones materiales $y$ personales precisas que posibiliten la realización, el desarrollo del sistema tributario. Aunque se traduzca la mayoría de las veces en el pago del tributo según los medios 
económicos que se posean; no es eso exclusivamente, lo engloba pero lo supera ${ }^{6}$.

Esta capacidad económica puede ser tenida en cuenta por el legislador en dos momentos distintos a la hora de establecer el régimen jurídico de los tributos, conocidos respectivamente como:

a. Capacidad económica absoluta: contemplada de manera genérica en relación a toda la colectividad, a las realidades que denotan riqueza; teniéndose en cuenta a la hora de configurar los posibles hechos imponibles que originan el nacimiento de la obligación tributaria. Por lo tanto, nos dirá qué hechos y con cargo a qué sujetos, va a nacer el tributo, sus elementos objetivo y subjetivo; como consecuencia de haber demostrado la idoneidad para pagar tributos, lo que se puede haber mostrado directa o indirectamente:

- hay hechos que por sí denotan la potencialidad para ser sometidos a tributación, su idoneidad para tributar no suscitaría dudas porque es palpable; son los llamados indices directos de capacidad $y$, son la obtención o adquisición de renta y la posesión o titularidad de un patrimonio.

- hay otros sin embargo, que no son tan claros a la hora de ser considerados manifestativos de capacidad económica, son los llamados índices indirectos, que a pesar de no manifestar- se siempre, necesaria e indudablemente como idóneos para tributar, sí es cierto que normalmente y en la mayoría de los supuestos lo serán, porque normalmente representan una cierta tendencia hacia la posesión de capacidad económica; tales como la circulación o tráfico de bienes, o el consumo o gasto de la renta.

b. Capacidad económica relativa: proporciona el criterio que orienta la fijación concreta de la carga tributaria de cada sujeto concreto, al operar en el momento de calcular el importe exacto del tributo; determina en cada caso y para cada persona, los elementos de cuantificación de su prestación tributaria, midiendo la cantidad en que se ha manifestado su capacidad económica. Será el modo de fijar el elemento cuantitativo del tributo, y por ello se tiene en cuenta al elegir entre los métodos impositivos o técnicas tributarias que miden la manifestación de riqueza de cada hecho y sujeto, cuáles van a utilizarse para liquidar con ello el importe del tributo. Se refieren por tanto a:

- La naturaleza personal o real del tributo, adaptándose mejor los tributos personales que los reales a las exigencias de la capacidad económica.

- El carácter objetivo o subjetivo del tributo, lográndose mediante exenciones o beneficios fiscales en general y

6 Caso de la existencia de un mínimo exento, que evita el pago pero no el tener que presentar las declaraciones correspondientes, o el soportar las retenciones que procedan, o bien el presentar justificantes o pruebas e informaciones sobre otros; o el hecho de tener que practicar retenciones por el pagador de ciertas rentas para ingresarlas en el Tesoro, que no se efectúan con dinero propio sino del sujeto pasivo... 
otras medidas desgravatorias, una mayor subjetivización del tributo y por tanto su mejor adaptación a la capacidad del sujeto.

- La estructura proporcional o progresiva del gravamen, permitiendo más fácilmente un tipo progresivo los impuestos personales que los reales, más respetuoso con la capacidad.

\subsection{La progresividad del sistema tributario y su límite: la no confiscatoriedad}

El principio de progresividad debe ser entendido como la forma a través de la cuál conseguir la efectiva igualdad, puesto que exige el reparto de la carga tributaria atendiendo a la capacidad económica de los sujetos, pero en su forma más exigente, más que proporcionalmente, progresiva. En la medida que la progresividad se predica de todo el sistema tributario en su conjunto y no de cada categoría tributaria aislada, individual; su vigencia y respeto no exige que todos los tributos tengan que tener necesariamente un tipo de gravamen progresivo para que lo sea el sistema.

Pueden existir en nuestro sistema perfectamente tributos proporcionales, en los que su tipo de gravamen sea un único porcentaje proporcional, aplicable a todos los supuestos en que resulta exigible, y que no varía a pesar de que cambie el nivel de capacidad económica del sujeto al que se aplica; e igualmente pueden existir tributos fijos, en los que el legislador establece una misma cuantía en términos absolutos para todos los casos en que nazca ese tributo, todos pagarán igual cantidad o importe porque la realización de ese hecho imponible denota siempre igual capacidad.

La progresividad es, por tanto, la manera de ser del sistema tributario en su conjunto, articulándose técnicamente de forma que pueda responder a la consecución de unos fines que no son estrictamente recaudatorios, sino más bien redistributivos de la riqueza nacional de la forma más justa posible, según los arts. $40-1^{\circ} \mathrm{y}$ 131-19 de la Constitución 7 ; será la característica del sistema tributario, a medida que aumenta la riqueza de una persona, aumenta su contribución al sostenimiento del gasto público en mayor proporción que el incremento de su riqueza y, a la inversa, conforme disminuye la riqueza de un sujeto, disminuye su contribución en mayor proporción que la disminución de su capacidad que la ha generado. Los que tienen más, contribuyen en proporción superior a los que tienen menos.

7 Artículo 40-1\%: "Los poderes públicos promoverán las condiciones favorables para el progreso social y económico y para una distribución de la renta regional y personal mas equitativa, en el marco de una política de estabilidad económica. De manera especial realizará una politica orientada al pleno empleo".

Articulo 131-12; "El Estado, mediante ley, podrá planificar la actividad económica general para atender a las necesidades colectivas, equilibrar y armonizar el desarrollo regional y sectorial y estimular elcrecimiento de la renta y de la riqueza y su mas justa distribución \#. 
El Tribunal Constitucional (1981) ha dicho que «el sistema justo que se proclama en la Constitución no puede separarse, en ningún caso, del principio de progresividad nidel principio de igualdad; la igualdad que proclama va intimamente enlazada a la capacidad económica y a la progresividad, por to que no puede ser simplemente reconducida a los términos del ant. 14; una desigualdad cualitativa es indispensable para entender cumplido este principio, precisamente la que se realiza mediante la progresividad global del sistema tributario alentando la aspiración a la redistribución de la renta".

La progresividad es un fenómeno ligado al desarrollo de los sistemas tributarios contemporáneos, los cuales asignan a la Hacienda pública una función redistributiva de la riqueza además de conseguir el ingreso de lo necesario para sufragar el gasto público; en esta línea se dice que los impuestos directos son más progresivos o al menos responden más a la idea de progresividad, pudiendo desarrollarla mejor que los impuestos indirectos; llegándose a afirmar que un sistema tributario que recaudase más cantidad en concepto de impuestos indirectos que directos, debería ser considerado regresivo y, viceversa.

Sin embargo esto no es total y exactamente así: efectivamente, en los impuestos directos los cuales se establecen sobre los índices directos de capacidad, la progresividad es más aparente y palpable, más fácilmente aprehensible en su estructura, puesto que los impuestos directos son con más frecuencia o facilidad, tributos personales y/o subjetivos, que admiten, por tanto, mayormente un tipo de gravamen progresivo; en cualquier caso, incluso la consideración global de sus es- quemas refleja más claramente la idea de progresividad; mientras que los impuestos indirectos, basados en índices indirectos de capacidad, responderían en principio peor a la progresividad, o al menos de forma menos tangible y contrastable, porque es más difícil que en su estructura se incorporen tipos impositivos progresivos, normalmente son proporcionales, y cualquiera otros elementos en general que la reflejen claramente, al ser habitualmente reales y/o objetivos.

No obstante, deben matizarse estas afirmaciones, por no ser exacta ni necesariamente así en todos los casos: quién tiene más capacidad económica realmente gasta y consume más, con lo que realmente tributará más por figuras indirectas; aunque la correlación no sea tan lineal como en los impuestos directos entre aumento de renta y de tributación, por las distorsiones que pueden suponer la existencia de bienes de primera necesidad o, la influencia de otros factores, ajenos sobre los hábitos de consumo, pero genéricamente se puede decir que suele ser asi $y$ en cierta forma lo es. También los impuestos indirectos admiten, al menos en ciertos casos, tipos de gravamen variables aunque no sea esto exactamente fijarlos como progresivos; como establecer por ejemplo tres tipos de gravamen para el IVA español $(16 \%$ como normal y, dos reducidos, el $7 \%$ y el $4 \%$ ).

Luego hoy día puede negarse que los impuestos directos sean siempre y necesariamente más progresivos que los indirectos en todos los casos, incluso a veces puede ser a la inversa, porque la progresividad no es sólo cuestión numérica, del tipo de gravamen, también se puede favorecer con otro tipo de medidas fis- 
cales como beneficios fiscales, diferenciaciones de régimen aplicable, casos particulares...; y en cualquier caso, la que es exigida por nuestra Constitución como principio de justicia tributaria, debe ir siempre y en todo caso referida al sistema tributario en su conjunto, al conjunto de tributos vigentes.

Sabemos además que la progresividad encuentra un límite concreto aunque difícil de precisar en el propio art. 31-1 de la Constitución, la no confiscatoriedad, al afirmar que nuestro sistema tributario para ser justo, nunca podrá alcanzar carácter confiscatorio, no podrá tener dicho alcance; partimos del concepto de la Real Academia de la Lengua Española sobre el verbo confiscar, adaptándolo al tema de referencia, siendo así entendido apriorísticamente como "la privación a una persona de sus bienes para aplicarlos al tisco". Se ha dicho por algunos autores como consecuencia de ello, que la confiscatoriedad de un tributo supondría, tener que vender los bienes o enajenar los servicios o derechos sobre los que recae para hacer frente a su pago; aunque sería discutible si efectivamente es ése su significado, sin embargo está claro que no lo es estrictamente para este caso, porque debe establecerse respecto de todo el sistema tributario, al igual que la progresividad a la que limita $y$, no para cada figura concreta.

Sin embargo, al menos aporta dicho argumento una idea interesante, que surge poniendo en conexión el derecho a mantener la propiedad privada y a trans- mitirla mediante la herencia, que protege el art. $33-1^{\circ}$ de la Constitución ${ }^{8}$ con la no confiscatoriedad. Podríamos entender que un sistema tributario llegaría a ser confiscatorio, si su aplicación conlleva la efectiva destrucción del patrimonio total de los sujetos, tal como estaba antes de la entrada en vigor de dicho sistema; en relación con su situación preexistente y como consecuencia directa de la nueva contribución a las cargas públicas. De ahí que supone en definitiva un límite a la facultad impositiva del ente público, al establecer y regular el deber de contribuir; deberá procurar la redistribución equitativa de la riqueza, pero respetando el derecho a la propiedad privada y la herencia.

El Tribunal Constitucional (1990) ha dicho que a en materia fiscal, la confiscación no supone la privación imperativa, al menos parcial, de propiedades, derechos patrimoniales o rentas sin compensación, ya que este tipo de privación o exacción es, en términos generales, de esencia al ejercicio de la potestad tributaria y al correlativo deber de contribuirn; si capacidad económica significa la exigencia lógica de buscar la riqueza alli donde se encuentra, "cabe añadir ahora que la prohibición de confiscatoriedad supone incorporar otra exigencia lógica que obliga a no agotar la riqueza imponible -...so pretexto del deber de contribuir... lo que se prohíbe no es la confiscación, sino justamente que la imposición tenga "alcance confiscatorio", es evidente que el sistema fiscal tendrá dicho efecto si mediante la aplicación de las diversas figuras tributa- 
rias vigentes, se llegara a privar al sujeto pasivo de sus rentas y propiedades".

\subsection{Legalidad tributaria}

El principio de legalidad tributaria también se recoge en la Constitución, aunque en otros preceptos; es el principio formal de justicia tributaria, que regula las relaciones entre las normas primarias, 0 leyes, y las secundarias, o reglamentos, a la hora de establecer y regular el sistema tributario y el deber de contribuir al sostenimiento del gasto público. En la actualidad, ha perdido su primer fundamento exclusivamente garantista que entroncaba con el llamado principio del "consentimiento del impuesto", como garantía o limitación a los poderes públicos frente a su posible intromisión en la esfera individual de la libertad, y sobre todo propiedad privada de los ciudadanos; respondiendo en la actualidad esencialmente a un fundamento democrático del tributo, que le dota de una base solidaria en el Estado de Derecho en que nos encontramos, en aras a la redistribución de la riqueza que también proclama nuestra norma suprema como hemos visto.

Está al servicio de un interés colectivo, podríamos decir asegurar la democracia al establecer las vías de reparto de la carga tributaria, a través del órgano que mejor asegura la confluencia de intereses contrapuestos en dicho reparto, dada su composición y funcionamiento; al estar formado por los representantes de los ciudadanos legítimamente elegidos, las Cortes Generales son las que tienen potestad legislativa y dotan de esa legitimidad democrática a todo el sistema tributario vigente. El deber de contribuir a las cargas públicas ha dejado de ser una exigencia necesaria pero odiosa, restrictiva, molesta del Estado; para convertirse en la base o sostén fundamental y necesario de nuestro Estado del bienestar, redistributivo de la riqueza y que fomenta la justicia económica y la solidaridad social.

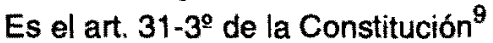
el que establece propiamente la reserva de ley para el establecimiento de todas las prestaciones de carácter público; tanto patrimoniales, caso de la creación y regulación sustantiva básica de los tributos, como personales, entre las que habrá determinados deberes de comportamiento de los sujetos en torno al cumplimiento de los tributos. Abarca esta reserva de ley tributaria según el Tribunal Constitucional, como vamos ver, a la creación o establecimiento de un nuevo tributo, junto con su régimen jurídico fundamental, es decir, la regulación de sus elementos esenciales y básicos tanto materiales como procedimentales.

De lo anterior podemos concluir que según la Constitución, la reserva de ley tributaria supone que el establecimiento de cualquier tributo deberá hacerse por ley; el significado de establecerlo o hasta dónde alcanza esta reserva de legalidad, según el Tribunal Constitucional abarca la creación de un tributo nuevo, 
junto con la regulación de los elementos básicos o esenciales que lo definen y configuran; pero el Tribunal no los ha concretado, por lo que deben deducirse de una interpretación sistemática de nuestro ordenamiento. Parece que pueden identificarse con los elementos que afectan a la existencia y cuantía del tributo, es decir, las circunstancias que definen la identidad objetiva y subjetiva: hecho imponible y sujetos pasivos, y la entidad del mismo: base tributaria, tipo de gravamen y cuota tributaria; junto con una serie de deberes de comportamiento $o$ exigencias de conducta a los interesados en la aplicación de los tributos, que son verdaderas prestaciones personales públicas ${ }^{10}$.

Si a esto unimos lo que se afirma cada vez por más autores referido a los elementos esenciales del procedimiento aplicativo del tributo, sus bases estructurales, las cuales estarian cubiertas por el principio de legalidad (art. 105,c) de la Constitución ${ }^{11}$, en tanto que la configura- ción de dicho procedimiento produce consecuencias sustantivas en el resultado aplicativo del tributo ${ }^{12}$; junto con esos deberes de colaboración o de comportamiento, que como exigencias de conducta en el desarrollo del procedimiento de gestión aplicativo del tributo, tienen naturaleza jurídica de prestaciones personales de carácter público que por el art. 31- $3^{\circ}$ Const. también se somete su establecimiento a la reserva de ley.

Por su parte, el art. $133-1^{\circ}$ y $2^{\circ}$ de la Constitución ${ }^{13}$ hace un reparto del poder tributario entre los distintos entes públi$\cos$, diferenciando entre originario para el Estado y el que no lo es, para Comunidades Autónomas y Corporaciones locales, claramente derivado en este último caso; al exigir una ley para que el Estado, así como las Comunidades Autónomas y Corporaciones locales, puedan establecer y exigir tributos de acuerdo a la Constitución en el primer caso y, a ésta y las leyes también en el segundo. Por tanto, el

10 Sólo por citar algún ejemplo el deber de declarar y de autoliquidar, tan generalizado en nuestro sistema; de llevar y conservar libros de contabilidad y registros; de presentar documentos, justificantes, datos... que sean requeridos; de permitir la comprobación e investigación de su situación tributaria; de aportar informaciones sobre otras personas con las que se tienen relaciones económicas...

11 "La ley regulará:... c) El procedimiento a través del cuál deben producirse los actos administrativos, garantizando, cuando proceda, la audiencia al interesadon.

12 Baste pensar en el diferente resultado de deuda tributaria para una persona, según se le aplique el régimen de determinación directa de su base tributaria, o por el contrario el de estimación objetiva por signos, indices o módulos; o las diferencias entre aplicar a la unidad familiar la tributación conjunta o separada, a efectos del impuesto sobre la Renta de las Personas Físicas; sólo por citar dos ejemplos con parangón en bastantes sistemas tributarios, salvando las distancias, naturalmente.

13 "La potestad originaria para establecer y exigir tributos corresponde exclusivamente al Estado, mediante leys asi como "Las Comunidades Autónomas y las Corporaciones locales podrán establecer y exigir tributos, de acuerdo con la Constitución y las leyes", respectivamente. 
poder originario para establecer tributos es exclusivo del Estado mediante ley, los otros dos entes públicos podrán establecer y exigir tributos de acuerdo a la Constitución y las leyes; teniendo las Corporaciones locales como límites constitucionales básicamente los principios de justicia tributaria y, como límites legales, los contenidos en la Ley de Haciendas Locales de 1988 (LHL).

\section{La delimitación constitucional del poder tributario local}

La propia Constitución garantiza igualmente la autonomía política de las Entidades locales en varios de sus preceptos, los arts. 137, 140 y 142, y de esta forma, reconoce autonomía a las Corporaciones locales para gestionar sus propios intereses generales, lo que a su vez requiere para ser efectiva, de cierta autonomía financiera para la gestión de sus ingresos y gastos públicos; aunque no tenga la capacidad de configurar libremente su sistema financiero en cuanto a los ingresos, pero sí en cuanto a los gastos, consagrando no obstante que habrán de ser suficientes.

\subsection{La autonomia local para la gestión de sus intereses}

Efectivamente, el art. 137 de la Constitución ${ }^{14}$ establece que el Estado se organiza territorialmente en municipios y provincias, así como en las Comunidades Autónomas que se constituyeran a partir de la misma, y que todas esas entidades gozan de autonomía para la gestión de sus respectivos intereses; consagrando el principio de autonomía local para la gestión de sus funciones, junto con los demás entes públicos territoriales mayores. Concretamente a nivel local, para el ámbito municipal se ve completado por el art. 140 de la Constitución, que garantiza la autonomía de los municipios, que gozan de personalidad jurídica plena y cuyo gobierno y administración corresponde a sus respectivos Ayuntamientos integrados por el Alcalde y los Concejales elegidos; así como para el provincial por el art. 141-2 $2^{\circ}$ de la Constitución, que encomienda el gobierno y administración autónoma de las provincias a las Diputaciones o Corporaciones de carácter representativo.

Por su parte, la Carta Europea de la Autonomía Local ${ }^{15}$, que nace con una cierta vocación de convertirse en denominador común subyacente a los distintos ordenamientos nacionales de los Estados miembros en la materia, como una especie de "Constitución Europea Local" podríamos decir; define a la autonomía local en su art. 3-1² como "el derecho y la capacidad efectiva de las Entidades Locales de ordenar y gestionar una parte

14 "El Estado se organiza territorialmente en municipios, en provinclas y en las Comunidades Autónomas que se conslituyan. Todas estas entidades gozan de autonomía para la gestión de sus respectivos intereses".

15 Fechada en Estrasburgo el 15 de octubre de 1985 y ratificada por España el 20 de enero de 1988 , a partir de lo cuál tiene condición y rango de Ley estatal. 
importante de los asuntos públicos en el marco de la Ley, bajo su propia responsabilidad y en beneficio de sus habitantes"; sentando un poco mas adelante, concretamente en el párrafo tercero del precepto siguiente, el principio de subsidiariedad también llamado de proximidad, al declarar que "el ejercicio de las competencias públicas, debe de modo general incumbir preferentemente a las autoridades mas cercanas a los ciudadanos".

\subsection{Su consecuencia: la necesaria autonomía financiera}

Lo anterior se ve complementado como anticipábamos a nivel de sus respectivas Haciendas por el art. 142 también de la Carta Magna ${ }^{16}$, que establece además el principio de suficiencia de recursos para el desempeño de las funciones que la ley atribuye a las Corporaciones locales; nutriéndose fundamentalmente de tributos propios, junto con la participación en los ingresos del Estado y de las Comunidades Autónomas como vamos a ver. Por tanto, dicha autonomía política de los municipios y provincias determina que las Haciendas locales respectivas deberán disponer de los medios económicos que precisen para el desempeño de las funciones que la ley les atribuye, al consagrar este art. 142 de la
Constitución también la autonomía financiera local; dado que para la plena y efectiva autonomía de gestión es imprescindible, al menos, una cierta autonomía financiera que no le haga depender de los recursos que le concedan otros entes, $\mathrm{ni}$ de la autorización de los mismos para decidir los gastos a efectuar.

De esta forma, se reconoce autonomía a las Corporaciones locales para gestionar sus propios intereses generales, lo que a su vez requiere como decimos para ser real y efectiva, de una cierta autonomía financiera para la gestión de su sistema de ingresos y gastos públicos; aunque no tengan la capacidad de configurarlo libremente en cuanto a los ingresos, como vamos a ver fundamentalmente en cuanto a sus propios tributos, pero sí básicamente en cuanto a los gastos, consagrando no obstante que habrán de ser en todo caso suficientes para hacer frente a estos últimos ${ }^{17}$.

\subsection{El principio de suficiencia de recursos}

Partiendo como ya hemos dicho del principio de autonomia política, garantizado por la Constitución a los Entes locales básicos, el art. 142 de la Constitución completa además esa autonomía en las decisiones sobre la gestión de sus in-

16 "Las Haciendas locales deberán disponer de los medios suficientes para el desempeño de las funciones que la ley atribuye a las Corporaciones respectivas y se nutrirán fundamentalmente de tributos propios y de participación en los del Estado y de las Comunidades Autónomas".

17 En este sentido, se puede ver la argumentación que ha hecho el Tribunal Constitucional en su Sentencia 4/1981, de 2 de febrero. 
tereses respectivos, estableciendo que las Haciendas locales deberán disponer de los medios suficientes para el desempeño de las funciones que la ley atribuye a las Corporaciones respectivas; $y$ el art. 133- $2^{\circ}$ de la Constitución por su parte, que reconocía poder tributario a las Corporaciones Locales en general (junto a las Comunidades Autónomas como hemos visto), es una de las formas fundamentales de asegurar su autonomía financiera, además de esta suficiencia de recursos a que nos referimos.

La referencia a ese principio fundamental de suficiencia financiera en cuanto a los recursos en relación a sus gastos, debe entenderse con dos significados; en primer lugar, internamente para la Corporación debe suponer una adecuación entre los ingresos o medios económicos de los que dispone para su empleo y, los gastos o fines para los cuáles están destinados; es decir, que sean bastantes en cuantia los recursos percibidos, para levantar todas las cargas públicas que le reporta a la entidad local dar cobertura a esos intereses propios que debe atender y gestionar, en el ámbito de sus competencias, desarrollando todas las actividades y prestando todos los servicios que requiera la consecución de sus funciones, fines y necesidades de interés general.
Pero no se limita a ello la suficiencia de recursos, sino que además desde la perspectiva externa de las relaciones con los otros entes públicos donde se integra, deben respetarse tanto por el Estado como por la Comunidad Autónoma respectiva, los medios económicos que precisan para su autonomía de gestión las Corporaciones locales, manifestándose en las leyes que fijen sus participaciones en los ingresos de estos entes que atribuyan a dichas Corporaciones ciertos tributos 0 , acoten el espacio en que puedan establecerlos ${ }^{18}$; no debiendo dificultar, restringir ni limitar la efectividad de su autonomía financiera, porque equivaldría realmente a cercenar las posibilidades de decisión y sobre todo actuación, sobre esas funciones y necesidades en las que la entidad local plasma sus intereses generales gestionándolas a su criterio.

Cuando tengamos ocasión de repasar algo más adelante el cuadro general de ingresos de los que disponen $y$, veamos su régimen jurídico general muy a grandes rasgos (pues la naturaleza de este estudio no nos permite mayores profundizaciones); podremos comprobar no obstante esa dificultad de cumplimiento en alcanzar un volumen de recursos adecuado a las funciones que deben cubrir, no sólo por el carácter mixto de su siste-

18 Se plasmará especialmente como fuentes principales de su financiación, a través de los presupuestos que fijan las participaciones de las Entidades Locales en los ingresos del Estado, ya que como vamos a ver aún no se ha puesto en marcha su participación en los ingresos de la Comunidad Autónoma; asi como en las leyes estatales o en su caso autonómicas, que creen los tributos propios de aquéllas y establezcan los límites de su aplicación, entre los cuáles cabe destacar la posible fijación de beneficios fiscales, que no obstante exige en el primer caso fórmulas de compensación según el art. 9-2 $2^{\circ}$ LHL que veremos, precisamente para respetar esa suficiencia de recursos. 
ma de financiación que también veremos, sino sobre todo por las fuertes limitaciones que deben respetar en el ejercicio de su poder tributario en concreto; teniendo en cuenta que hoy día la principal fuente de ingresos públicos para cualquier ente de esta naturaleza (alejados ya los tiempos de una Hacienda patrimonial ${ }^{19}$ ), son sin ninguna duda los tributos propios.

Lo anterior se ve completado con el art. 9-2 ${ }^{\circ} \mathrm{LHL}$, por el cuál las leyes que establezcan los beneficios fiscales que afecten a los tributos locales, deben determinar las fórmulas de compensación que procedan, teniendo en cuenta las posibilidades de crecimiento futuro de los recursos de dichas entidades procedentes de los tributos respecto de los cuáles se establezcan los mencionados beneficios fiscales; quedando igualmente obligado el Estado a arbitrar las fórmulas de compensación o anticipo que procedan en favor de la entidad local respectiva, cuando otorgue moratorias o aplazamientos en el pago de los tributos locales a alguna persona o entidad.

\section{Principales límites al poder tributario local}

Como ya hemos señalado con anterioridad, el principio de legalidad es pri- mordial en cuanto al establecimiento y la regulación de los elementos esenciales, básicos y fundamentales de los tributos, por las exigencias de los arts. $31-3^{\circ}$ y $133-1^{\circ}$ y $2^{\circ}$ de la Constitución; a pesar de lo cuál, nuestro sistema jurídico constitucional sólo ha permitido que dos de los tres entes públicos, a los cuáles se les reconoce poder tributario por la norma suprema, tengan la facultad normativa de poder dictar leyes a través de sus respectivos órganos legislativos, el propio Estado a través de las Cortes Generales y, las Comunidades Autónomas, a través de sus Parlamentos regionales.

Y junto a ello, igualmente para dos de esos mismos entes públicos con poder para organizar su sistema de ingresos y gastos públicos, en este caso las Comunidades Autónomas y las Corporaciones locales, se fija constitucionalmente un sistema mixto de financiación; puesto que no solamente van a poder disponer de ingresos propios para financiar sus gastos públicos, sino además también. de ingresos percibidos de otros entes públicos que, concretamente en el caso de la Hacienda local, constituyen un volumen recaudatorio muy importante en sus recursos disponibles. Por ambos motivos, se ve fácilmente que la posición que

19 En este sentido es importante destacar, no obstante, que hay un cierto retorno pendular podriamos decir, hacia los ingresos patrimoniales como una fuente de recursos de cierta relevancia, sin alcanzar por supuesto a los tributarios; con las nuevas formas de gestión y participación de los entes públicos en general, tanto en empresas como sociedades, organismos etc. de distinto carácter (comercial, industrial, mercantil), que proporcionan pingües beneficios económicos, quizá en parte por guiarse por criterios gerenciales privados, o por carecer en gran medida de los controles y requisitos de gestión de los cosa pública en su sentido mas clásico, o por regir otro tipo de relaciones laborales y de personal de alta dirección, o por otros muchos motivos a la vez difíciles de precisar aquí. 
tienen las Entidades locales en nuestro sistema está bastante más limitada en su ejercicio que la reconocida a los otros entes públicos mayores, resultado del diseño constitucional de su poder financiero $y$ tributario.

\subsection{El carácter mixto de financiación}

Retomando el citado art. 142, por mandato constitucional las Haciendas locales deben disponer de los medios suficientes para el desempeño de las funciones que la Ley atribuye a las Corporaciones respectivas, nutriéndose fundamentalmente de tributos propios junto a la participación en los ingresos del Estado y de la Comunidad Autónoma a la que pertenezcan; por tanto, generalizando el cuadro descrito de recursos disponibles al no ser una enumeración cerrada sino ejemplificativa, se dibuja un sistema integrado de recursos propios fundamentalmente tributarios y, de recursos ajenos o participados, en los de otros Entes públicos mayores en los que se integra. $O$ dicho en otros términos, un sistema mixto de financiación en cuanto al origen de los recursos que lo nutren, lo cuál va a dificultar en gran medida la consecución del otro gran principio financiero local englobado en el anterior precepto constitucional, la suficiencia de recursos para cumplir las funciones que la Ley les atribuye; al depender sus ingresos en gran medida de los recursos y medios económicos que decidan asignarle esos otros entes públicos mayores, y no disponer exclusivamente de sus propios recursos que ella misma se hubiera creado y regulado, dentro de los que destacan los tri- butos propios, donde está fuertemente limitado a su vez su poder de establecimiento, por la ausencia de potestad legislativa como vamos a ver.

La realidad de los últimos años en nuestro país, que no ha supuesto realmente cambio alguno respecto a épocas pasadas; viene caracterizada a este nivel por una marcada dependencia de la Administración central fundamentalmente, junto a la escasez de recursos propios y las dificultades de obtención de los ajenos. Ya resulta clásica la calificación acuñada al respecto por la práctica totalidad de los estudiosos dedicados al tema e, incluso por los intervinientes directos en el proceso legislativo, que la va marcando (a la hora de justificar algunas de las normas promulgadas con la finalidad primordial de paliarla), sobre la endémica situación deficitaria de la financiación local. $Y$ esa precariedad financiera, que choca frontalmente con el principio constitucional de suficiencia, precisamente obedece en gran medida al otro gran principio acuñado paralelamente como hemos visto; un sistema mixto de recursos, que navega entre la pura y simple transferencia de fondos, que podría garantizar en mayor medida aquella bastantía (pero pagando la costosa pérdida de autonomía de decisión y gestión consiguientes); y la creación de una tributación local propia, en sentido estricto, protagonizada por cada Corporación en función de su capacidad gravatoria, que hoy dia faltaría al respeto del principio de legalidad tributaria si lo entendemos en su sentido ortodoxo y tradicional, y que habria de vigilarse de cerca por los órganos encargados de ello, 
para que no rompiera el también principio constitucional de solidaridad ${ }^{20}$.

Partiendo de esa referencia genérica vista que hace la Constitución a los tributos propios y a la participación en los ingresos de los otros entes públicos como principales fuentes de financiación local; la Ley de Haciendas Locales establece en general ${ }^{21}$ los recur- sos de las Haciendas respectivas en el art. 2-1 $1^{\circ} \mathrm{LHL}$, que por tanto vamos a reagrupar en los dos grandes ámbitos referidos que llevan a calificar como mixto su sistema de ingresos, aunque sin poder entrar a desarrollar su régimen jurídico fundamental, dado que se excedería con creces la finalidad y extensión requeridas de este trabajo.

20 No creemos que necesariamente deba entenderse roto el principio constitucional de legalidad tributaria, cuyo arranque entronca con la misma exigencia para el establecimiento de toda prestación de carácter público (art. 31-39), a la vista del alcance relativo que le ha otorgado el propio Tribunal Constitucional en su Sentencia 185/1995, de 14 de diciembre, sobre los precios públicos, creemos que acertadamente; puesto que en su concreción distributiva entre los diferentes entes públicos a los que le reconoce poder tributario la misma norma suprema (art. $133-1^{2}$ y $2^{2}$ ), coloca en pié de igualdad al menos en la literalidad del precepto, a las Comunidades Autónomas y las Corporaciones Locales; si bien es cierto que privando a éstas de capacidad legislativa por otros preceptos constitucionales, sobre lo que seguramente tendremos ocasión de volver mas detenidamente en el presente trabajo.

A mayor abundamiento, todavía menos necesariamente ha de romperse la solidaridad entre todos los españoles (ants. 2 y 138-12), tras el debate abierto en relación al nuevo sistema de financiación autonómico para las Comunidades de Régimen General, y la tradicional postura que viene adoptando en su interpretación el mismo Tribunal antes y sobre todo, después de dicha reforma; pues la Constitución garantiza igualmente autonomía a los municipios y provincias para la gestión de sus respectivos intereses (arts. 137, 140 y 142), y si no trata con mayor detenimiento las competencias y funciones a las que pueden y deben atender, frente a lo propio respecto a dichas Comunidades Autónomas (baste como muestra el largo listado del art. 148, entre otros muchos preceptos mas especificos), es precisamente por la tradición de aquéllos en nuestra estructura territorial, frente al surgimiento de estas últimas precisamente con su creación a través de la Constitución española de 1978

21 En general, los ingresos recogidos de las distintas Entidades locales permitidas por nuestro sistema, son los mismos vistos en el art. 2 LHL al que se remiten con ciertas singularidades; sin embargo, existen algunas matizaciones para cada una de las diferentes Corporaciones, reflejadas en los preceptos que la misma Ley les dedica respectivamente, y que vamos a reflejar a continuación aunque muy resumidamente:

arts. 57 y ss. para los Municipios: destacar la distinción entre los impuestos obligatorios ( $1 \mathrm{~m}$. puesto sobre Bienes Inmuebles -IBI-, Impuesto sobre Actividades Económicas -IAEe Impuesto sobre Vehículos de Tracción Mecánica -IVTMo de Circulación como se le conoce abreviadamente) y optativos (Impuesto sobre Construcciones, Instalaciones y Obras-IClOy Plusvalía como aún se le denomina muchas veces al impuesto sobre el incremento de Valor de los Terrenos de Naturaleza Urbana -IIVTNU-) de los Ayuntamientos que los gobiernan, al disponer de todos los recursos locales vistos;

rts. 121 y ss. respecto de Provincias: destacando en este caso como en todos los demás, que como tributos propios no pueden establecer impuestos, y tienen fijado las Diputaciones un recargo provincial sobre el IAE; 


\subsubsection{Recursos propios \\ fundamentales: sus tributos}

En ese cuadro general de ingresos fijado por el precepto citado, encontramos como recursos financieros de carácter propio los siguientes:

a. Los ingresos procedentes de su patrimonio y demás de derecho privado: Vienen regulados en los arts. 3 y siguientes $\mathrm{LHL}$, y engloban los rendimientos o productos de cualquier naturaleza derivados del patrimonio de las Entidades Locales así como las adquisiciones a título de herencia, legado o donación.

b. Los tributos propios: Tasas, contribuciones especiales, impuestos; asi como los recargos exigibles sobre impuestos de las Comunidades Autónomas o de otras Entidades locales:

La regulación bastante mas extensa de este recurso comienza en el art. 6 LHL con una serie de normas generales sobre los primeros, continuando con el régimen jurídico sobre imposición y ordenación de los mismos (arts. 15 yss. LHL), para por fin entrar a configurar el concepto y elementos esenciales de cada uno de los tributos propios de las Corporaciones Locales en general; las tasas desde el art. $20 \mathrm{LHL}$, las contribuciones especiales a partir del art. $28 \mathrm{LHL}$, para terminar con una referencia genérica a los impuestos y recargos en el art. 38 $\mathrm{LHL}$, dado que aquéllos se regulan in extenso al tratar en concreto de los recursos disponibles por los Ayuntamientos (arts. 60 y ss. LHL), dado el carácter municipal de todos ellos, y configurando a los segundos a través de su previsibilidad bien por la misma Ley $^{22}$ o bien por las leyes de las Comunidades Autónomas, que podrán establecer recargos sobre sus impuestos propios o los de otros Entes Locales.

c. Los percibidos en concepto de precios públicos: Se pagan por la prestación de servicios o realización de actividades de competencia local, siempre que sean de solicitud o recepción voluntaria por los administrados al novenir impuesta por la normativa, ni ser imprescindibles para la vida privada o social del solicitante los servicios o actividades requeridos; $y$ que además se presten o realicen también por el sector privado (arts. 41 y ss. LHL).

d. El producto de las operaciones de crédito: Se producen como consecuencia de aquellas operaciones que puedan concertar las Entidades locales, sus organismos autónomos y sociedades mercantiles de capital integramente local, en todas las modalidades y con toda clase de entidades de crédito, según los arts. 49 y siguientes LHL.

- arts. 131 y ss. sobre Entidades supramunicipales: Areas Metropolitanas, Mancomunidades y demás Entidades Municipales Asociativas, y Comarcas y otras Entidades supramunicipales,

- art. 137 Entidades inframunicipales: Anejos, Pedanias...

22 Regulados en los arts. 124 y $134-1^{\circ}$,a) LHL. 
e. El producto de las multas y sanciones en el ámbito de sus competencias y demás de Derecho público: Podriamos agrupar aquí también los demás ingresos de Derecho público en general; aunque no se establezcan aquéllas con la finalidad recaudatoria como en los demás casos, sino como consecuencia de su potestad sancionadora para restablecer el orden jurídico quebrantado mediante una conducta ilícita; no obstante producirán un determinado ingreso, siempre que consistan en sanciones pecuniarias, ya se trate de multas fijas o proporcionales según los casos.

Como decimos, de cada uno de los dos grupos de recursos, la Constitución destaca los que al parece considera más importantes a efectos de la financiación local; entre estos primeros, mas numerosos y variados, menciona a los tributos propios, donde el carácter derivado de su poder a la hora de establecerlos y regular sus elementos fundamentales, como veremos, supone una gran limitación para las Corporaciones Locales las cuales disponen de un margen muy estrecho y sin duda totalmente insuficiente, como para poder determinar o influir de una forma decisiva en el volumen de recaudación que puedan proporcionarles dichos tributos propios.

\subsubsection{Principales recursos ajenos: participaciones}

Por su parte, de aquel listado de ingresos locales en el señalado precepto 2-1 LHL, podemos agrupar en este segundo apartado tan sólo dos recursos económicos, ajenos de las Haciendas locales, en cuanto que suponen la partici- pación de éstas en los ingresos de otros entes públicos, al depender de una decisión de otro sujeto de Derecho su obtención en la Hacienda respectiva, al ser cedidos por éstos a las Entidades Locales:

a. Las participaciones en tributos estatales o autonómicos: Según el art. 39 LHL, las Entidades locales participarán en los tributos del Estado en la cuantía y según los criterios que la propia Ley establece, así como en los tributos propios de las Comunidades Autónomas en la forma y cuantía que se determinen por las leyes de sus respectivos Parlamentos.

b. Las subvenciones: Son cualquier clase de ayudas de toda índole que, en base al art. $40 \mathrm{LHL}$, obtengan las Corporaciones Locales con destino a sus obras y servicios; no pudiendo ser aplicadas a distintas atenciones de aquéllas para las que fueron otorgadas, con la salvedad de los sobrantes no reintegrables cuya utilización no estuviera prevista en la concesión de la subvención.

Por su parte, entre estos otros dos recursos ajenos, prioriza la participación en los ingresos del Estado y Comunidad Autónoma (debe entenderse a la que pertenezcan); pero curiosamente, sólo los primeros son una realidad, debido a que hasta el momento, ningún presupuesto autonómico de ejercicio alguno ha recogido en su contenido, como un gasto de dicha Comunidad y consiguiente ingreso transferido a sus Entidades locales, dicha participación en sus ingresos; exigencia constitucional como venimos reiteradamente comentando, no lo olvidemos, a pesar de su inexistencia real.

Con lo cual, no creemos deba insistirse mucho más para que quede clara- 
mente puesto de manifiesto el precario resultado de la aplicación de su sistema de financiación, de naturaleza mixta, en cuanto a la aportación de los fondos que les produce para hacer frente a las funciones que la ley atribuye a las Corporaciones locales; mediante una cuantía de recursos suficiente, recordemos, para dar cobertura a los gastos que la consecución de dichas finalidades les producen; $y$ debiendo ser no sólo posibilitados sino incluso protegidos por esos otros entes territoriales de los que éstas forman parte, a la hora de regular a nivel legal la concreción de esa financiación local ${ }^{23}$, como plasmación externa de respeto a esa suficiencia financiera, lo que tampoco conviene pasar por alto.

\subsection{La ausencia de capacidad legislativa}

Precisamente como decimos, ese poder tributario que le reconoce la Carta Magna a las Corporaciones locales, tiene claramente naturaleza derivada frente al de los otros entes públicos a quiénes también se lo otorga, al carecer aquéllas tal y como las configura nuestro ordenamiento constitucional, de poder legislativo para dictar normas con rango legal; luego sus límites tanto constitucionales como derivados de las leyes, sean estatales o en su caso autonómicas, a la hora de establecer y regular sus propios tributos, serán mucho más importantes y restrictivos que los de esos otros entes de mayor ámbito territorial.

Como sabemos, según el art. 133-2 ${ }^{\circ}$ Const. las Corporaciones Locales pueden establecer y exigir tributos de acuerdo a la misma Constitución y las leyes, al igual que las Comunidades Autónomas también incluidas en la referencia constitucional contenida en este precepto, y frente al Estado tan sólo sometido al respeto de los principios constituciones en el ejercicio de su poder tributario, como recoge el primer párrafo del mismo; y por otra parte, el art. 31- $3^{\circ}$ también de la norma suprema, exige una ley para establecer cualquier clase de prestación de carácter público, sea personal o bien patrimonial, siendo la principal prestación patrimonial pública lógicamente el tributo. Luego surge una aparente contradicción entre ambos preceptos constitucionales, puesto que si las Corporaciones Locales

23 Entre esos límites legales estatales, que coinciden bastante lógicamente con los establecidos por otra parte para las Comunidades Autónomas mediante la Ley Orgánica de Financiación de éstas, destacan por su importancia los contenidos en el art. 6 LHL al afectar a los tributos propios que ella misma fija:

de una parte el criterio de territorialidad: al no poder gravar bienes situados, actividades desarrolladas, rendimientos originados, o gastos realizados fuera de su territorio, ni tampoco negocios, actos o hechos celebrados o realizados $s_{1}$ o el ejercicio o transmisión de bienes, derechos u obligaciones que no hayan nacido ni hubieran de cumplirse en el mismo; junto al también principio de neutralidad, al no poder obstaculizar la libre circulación de personas, mercancias, servicios y capitales, ni poder afectar a la fjación de residencia de personas o ubicación de empresas y capitales dentro del territorio nacional, sin que ello obste eso si para que pueden instrumentar la ordenación urbanistica de su territorio 
no pueden dictar leyes, en principio no podrian establecer tributos como se les reconoce al exigirse normas de tal rango para ello.

De ahí que la referencia del primer precepto constitucional en su apartado segundo al establecimiento de tributos, sea distinta en significado, contenido y alcance según aluda a uno $u$ otro ente público: las Comunidades Autónomas pueden hacerlo en su sentido pleno, de crear tributos ex novo mediante una ley que los fije y regule los elementos esenciales de su régimen jurídico; frente a las Entidades Locales que no pueden dotarse de nuevos tributos directamente ni modificar su regulación básica, porque no se cumpliria con las exigencias de la legalidad, necesitando una ley previa que así lo haga. Con ello, la posición de las Comunidades Autónomas en cuanto a su poder en relación con los tributos, está mucho mas próxima a la estatal que a la local, que se distancia en mayor medida; por lo cuál, cada vez mas se califican de originarios ambos poderes tributarios frente al de las Corporaciones locales claramente derivado, aunque de primer y segundo grado respectivamente para diferenciar el del Estado y el autonómico.

Luego el establecimiento de tributos por dichas Corporaciones consistirá:

a. En primer lugar en su puesta en vigor, dotándolos de fuerza y aplicabilidad directa cuando previamente otro ente con poder legislativo los haya creado, declarándolos exigibles a través del Acuerdo de Imposición; lógicamente cuando no sea obligatoria sino potestativa su aplicación por el ente local, tal y como vengan configurados en la ley ${ }^{24}$, valorando la oportunidad y necesidad en cada caso concreto de la contribución a las arcas locales con su pago.

b. Igualmente, desarrollando y complementando reglamentariamente los elementos básicos y esenciales de su regulación legal, respetándola siempre, asi como regulando directamente aquellos otros aspectos no fundamentales de su régimen jurídico, que como tales no precisan de una ley para ser fijados; a través del Acuerdo de Ordenación en este caso así como en el siguiente, que junto al anterior en su caso integran el contenido de la Ordenanza Fiscal correspondiente, si van en relación con un tributo concreto, o que pueden integrarse en la Ordenanza Fiscal General si afectan a todos ellos en su conjunto.

c. $Y$ por último, determinando, precisando o escogiendo ciertos elementos de su estructura, respetando los principios que rigen en su ámbito legal y dentro de los límites fijados para ello por la ley, cuando ésta lo permite; tal es el caso, por ejemplo,

24 En el caso de la Ley estatal ( $L H$ L $)$, son actualmente potestativos en su exigencia por la Corporación respectiva, dos impuestos municipales (ei impuesto sobre Construcciones, Instalaciones y Obras - IClO-, y el de Incremento de Valor de los Terrenos de Naturaleza Urbana -IIVTNU-), junto con cualquier tasa o contribución especial que quiera aplicar por su actuación local. 
de la concreción del tipo de gravamen cuando puede ser modulado por la Corporación, el establecimiento concreto de la Tarifa aplicable si no la contiene la ley, la elección sobre la aplicación o no de aquellos beneficios fiscales que oferta una norma legal, o la decisión sobre la exigencia de su pago mediante el régimen de autoliquidación cuando ésta lo permite, por citar algunos.

\section{Conclusiones y Propuestas}

Tras el necesariamente rápido repaso que hemos hecho a la financiación de los servicios públicos locales en el ordenamiento tributario español, sólo nos resta lanzar algunas ideas al debate, dado que puede haber muchas mas reflexiones a efectuar que seguramente surgirán, al menos para hacer alguna aportación por nuestra parte a la posibilidad de mejorar el sistema descrito; centrándonos al respecto en las que puedan depender fundamentalmente en su desarrollo, de los propios municipios esencialmente, sin intervención de la voluntad de otros entes públicos como el poder central, puesto que eso dificultaría mas aún su consecución; aunque advertimos, no obstante, que solamente son eso, una aportación mas al debate subsiguiente, sin ninguna otra pretensión mayor por nuestra parte, dadas las caracteristicas y finalidades del presente trabajo, abrir la discusión sobre el tema.

De una parte, sería conveniente que los Entes locales aprovecharan al máximo las potencialidades, aunque sean escasas, que les permite la ley en la regulación de sus propios tributos, tanto en primer lugar, manifestándose en la uti- lización o puesta en vigor de sus impuestos potestativos, ya que en los obligatorios no cabe planteárselo lógicamente; como en la elección o determinación, dentro de aquellos márgenes que le permita la norma legal en cuanto a su regulación, básicamente podria ser en la fijación del tipo de gravamen que modula el ingreso, así como en el posible establecimiento de beneficios fiscales como motor de desarrollo; junto en tercer lugar, a su desarrollo reglamentario directo en aquellas otras cuestiones no esenciales que lo permitan, en el siempre debido respeto a la legalidad, por supuesto.

Igualmente, y retomando esta idea, exigir todos los tributos potestativos que resulten necesarios para financiar los servicios a prestar a la comunidad, ya no solamente impositivos. También estableciendo y regulando como decimos, todas las tasas fiscales que sean precisas, evitando con ello "malacostumbrar" al ciudadano; dado que el coste de la prestación de dichos servicios, además con calidad e incluso una cierta potencialidad de crecimiento y mejora en el futuro, es evidente que tiene relevancia cada vez creciente en el presupuesto de cualquier Entidad local (suministro de agua potable o recogida de residuos sólidos, sólo por citar algunos de los ejemplos mas claros y comunes); y por supuesto, siguiendo en lo anterior un proceso equilibrado y paulatino, que evite el rechazo social que produciría en otro caso, tan difícil de disolver una vez creado como sabemos (por ejemplo, estableciendo estas nuevas figuras con un gravamen reducido, e incrementándolo lenta pero continuadamente hasta alcanzar su necesario nivel recaudatorio, adaptado a la vez, a la realidad 
de su coste). $Y$ de otra parte, en la medida que pueda ser conveniente, recurriendo a la contribución especial, la gran olvidada, con ciertos motivos eso sí, de nuestro actual situación local; puesto que en determinados supuestos puede ser de gran utilidad y eficacia en paliar el déficit económico que suponen las grandes obras de infraestructura sobre todo para los Ayuntamientos pequeños.

$Y$ por último, intentar frenar esa tendencia tan peligrosa en los últimos años, desde nuestro punto de vista, de ir asumiendo cada vez mas competencias por las Entidades locales, casi podriamos decir sin limitación alguna; en muchas ocasiones no atribuidas expresamente por la ley a su ámbito de actuación reconocido; y que a pesar de reconocer la dificultad que supone siempre, resistirse a su exigencia, por la proximidad del ciudadano ante su Administración mas cercana; no puede olvidarse que esa suficiencia de recursos en el sistema de financiación local, la consagra la Constitución para cubrir $y$ atender las funciones que la ley atribuye a las Corporaciones respectivas, pero no a otras. Y en todo caso, está claro que esas competencias estarán atribuidas por ley a algún ente público, al que le corresponde su desarrollo; el cuál, si está haciendo una cierta dejadez de funciones, habrá de exigírsele al menos alguna compensación económica o de cualquier otro tipo, a cambio de dar en su lugar esa cobertura y satisfacción a servicios de los que él debería responder, en todo caso, según la normativa. Sin más dilaciones, el debate que es lo más importante en este caso, queda abierto.

\section{Bibliografía citada}

Constitución Española (1978). Norma de 27 de diclembre. Boletin Oficial del Estado. Madrid. España.

Carta Europea de Autonomía Local (1988). Norma de 20 de enero de 1988. Boletín Oficial del Estado. Madrid. España.

Ley General Tributaria (1963). Norma n²30, de 28 de diciembre. Boletín Oficial del Estado. Madrid. España.

Ley Orgánica de Financiación de las Comunidades Autónomas (1980). Norma $n^{2} 8$, de 22 de septiembre. Boletín Oticial del Estado. Madrid. España.

Ley Reguladora de las Haciendas Locales (1988). Norma $n^{2} 39$, de 28 de diciembre. Boletín Oficial del Estado. Madrid. España.

Tribunal Constitucional (1981). Sentencia $n^{24}$, de 2 de febrero. Boletín Oficial del Estado. Madrid. España.

Tribunal Constitucional (1981). Sentencia $n^{8} 27$, de 20 de julio. Boletín Oficial del Estado. Madrid. España.

Tribunal Constitucional (1987). Sentencia $n^{2} 19$, de 17 de febrero. Boletín Oticial del Estado. Madrid. España.

Tribunal Constitucional (1987a). Sentencia $\mathrm{n}^{\mathrm{o}} 128$, de 16 de julio. Boletín Oficial del Estado. Madrid. España.

Tribunal Constitucional (1988). Sentencia $\mathrm{n}^{2} 19$, de 16 de febrero. Boletín Oficial del Estado. Madrid. España.

Tribunal Constitucional (1990). Sentencia $n^{2} 150$, de 4 de octubre. Boletín Oficial del Estado. Madrid. España.

Tribunal Constitucional (1995). Sentencia $n^{\circ}$ 185, de 14 de diciembre. Boletín Oficial del Estado. Madrid. España.

Tribunal Supremo (1986). Sentencia de 2 de junio. Boletin Oficial del Estado. Madrid. España. 